\title{
OUTDOOR RECREATION NEEDS OF METROPOLITAN AREAS
}

\author{
By K. G. HIGGS
}

\section{INTRODUCTION}

One of the phenomena of the 20th Century has been the tremendous growth of urban areas. This has been characterized by the formation of large metropolitan areas in many sections of the North American continent, and on the basis of the present trends is leading to even more complex urban environments.

Large metropolitan centres are prodigious users of land and water resources. These centres, with all their power and wealth, lay an imperious hand on woodland and watersheds drawing them out of earlier uses and transforming them into building lots, streets, shopping centres, school yards, expressways, and airports. The process of subjugation of resources to metropolitan use has not always followed any planned sequence or orderly procedure. Resulting patterns of resource utilization are not likely always to provide efficient satisfaction of the needs for outdoor recreation generated in a metropolitan society. In general, the provision of outdoor recreation facilities and the development of adequate access to outdoor recreation opportunities for the residents of densely settled metropolitan areas have not been accorded equal weight in the metropolitan resource utilization contest.

Looking ahead, there seems to be little doubt that the provision of outdoor recreation opportunities will become a more difficult and complex task as existing metropolitan centres increase in size, and as new population centres of substantial size appear. At the same time, the need for outdoor recreation will become increasingly important for metropolitan residents.

The purpose of this paper is to examine some of the problems in meeting the needs for outdoor recreation in the metropolitan environment; to discuss the part played by the forest in meeting these needs; and to explore the use of the outdoors for educational purposes. I intend to use the experience of the Metropolitan Toronto and Region Conservation Authority to illustrate some of the points that I wish to make.

\section{DEMAND}

The demand for outdoor recreation space and facilities is growing at an unprecedented rate as a result increasing population and leisure-time activities.

The population increase is accompanied by rising personal incomes, more leisure time, and greater mobility. Considering all of these factors, we will experience a demand for recreational resources of an astounding magnitude over the years ahead.

\footnotetext{
1 Director of Operations, Metropolitan Toronto and Region Conservation Authority, Box 720, Woodbridge, Ont.
} 
The previous paper on today's programme has given you some indication of the phenomenal growth in demand and use of outdoor recreation facilities at the Provincial level. In my own experience, the Metropolitan Toronto and Region Conservation Authority (established in 1957) had a total visitation of 127,000 at that time, and this has since grown to a visitation in excess of one million people in 1963 on Authority-administered lands. In addition, one million people visited lands owned by the Authority but administered by the Metropolitan Parks Department. These areas were not available, nor developed for public use prior to 1957. Projected visitation to Authorityadministered lands to 1980 is three-and-one half million people.

One of the aspects of the population growth is the tendency for regional concentration of our population. Fifteen metropolitan centres in Canada contain $37.5 \%$ of the Canadian population, and eighty percent of the total population of Canada live in cities of twenty-five thousand persons or more. It is estimated that the population of Metropolitan Toronto will be increased to two million five hundred thousand by 1980 , and to four million by the end of the century. These characteristics of population growth will result in great shortages of land of the right type; in the right amount; and in the right places, to meet outdoor recreational needs.

\section{OUTDOOR RECREATION ENVIRONMENT}

Outdoor recreation requires the use of a broad range of natural resources in varying combinations to satisfy a wide range of social and cultural interest groups.

The Outdoor Recreation Resources Review Commission has proposed a classification of recreation resources, as follows:

CLASS I HIGH-DENSITY RECREATION AREAS

(areas intensively developed and managed for mass use.)

CLASS II GENERAL OUTDOOR RECREATION AREAS

(areas subject to substantial development for a wide variety of specific recreation uses.)

CLASS III _ GENERAL OUTDOOR RECREATION AREAS (various types of areas that are suitable for recreation in a natural environment and usually in combination with other uses.)

CLASS IV UNIQUE NATURAL AREAS

(areas of outstanding scenic splendor, natural wonder or scientific importance.)

CLASS V

PRIMITIVE AREAS

(undisturbed roadless areas, characterized by natural, wild conditions, including "wilderness areas".)

CLASS VI HISTORIC AND CULTURAL SITES

(sites of major historic or cultural significance, either local, regional, or national.)

While not all metropolitan regions can satisfy these requirements in total, many areas have a sufficient number of suitable areas to satisfy most of the outdoor recreational needs. The problem is to ensure that as many of these suitable areas as possible are acquired and preserved for future demand.

Water is a prime requisite for outdoor recreation. The experience of the Metropolitan Toronto and Region Conservation Authority verifies this fact 
as surveys have indicated that eighty percent of users of Conservation Areas either swam, went fishing, or went boating.

What part then does the forest resource play in satisfying the needs for outdoor recreation in a metropolitan region?

Statistics indicate that simple activities play an important part in the recreation picture and these include picnicking, hiking, and driving, for pleasure. These simple activities require an attractive setting of which trees, woods, and forests, play an important part.

Woods, rather than water areas, provide the site for hunting, stream fishing, camping, and nature walks.

These activities are frequently considered to epitomize the enjoyment of the out-of-doors.

Let us examine some of these basic assumptions in the light of the experience of the Metropolitan Toronto and Region Conservation Authority. The Toronto region is characterized by a shortage of suitable water to meet the tremendous demand for water-oriented activities. Although blessed with an extensive shoreline of Lake Ontario, the Lake is too cold and public access too limited to provide a permanent solution to the problem. The Authority has provided additional water areas by the acquisition of large stretches of rivers, by the acquisition of lakes, and by the construction of small and medium sized dams. A comprehensive Flood Control and Water Conservation Plan, under which thirteen large dams and reservoirs are to be created, will provide further extensive areas for water-oriented activities.

The Metropolitan Toronto region is traversed by nine drainage basins of various sizes of which the major streams rise in the interlobate moraine that traverses the region from West to East about twenty-five miles North of Lake Ontario.

A very substantial area of prime agricultural lands lie between the existing urbanized area and the interlobate. In the agricultural section, clearing has reduced the forest cover to a negligible amount and only the major valleys with very extensive wooded slopes remain to provide the resources for outdoor recreational activities.

The interlobate moraine, however, is largely an area of marginal and sub-marginal agricultural lands traversed by many small spring-fed creeks. A relatively substantial amount of forest cover remains on these lands. However, quite extensive areas of land have been abandoned for agriculture and these areas are best returned to forest cover.

The Authority has acquired substantial areas of lands in these headwater areas and is pursuing a programme to provide a wide range of outdoor recreational activities on these lands.

Existing forest lands are being improved by proper management. Likewise, plantations are being improved through management. Extensive areas are being reforested to provide additional environment for the surging demand for outdoor recreational activities.

The Authority has established a nursery for the production of plants particularly adapted to provide food and cover for wildlife, and which also are adapted for erosion control purposes. These plants complement the forest in providing improved natural areas for recreational activities. 
The Authority has acquired 1,700 acres of forest lands which are under management by the Department of Lands and Forests. Although initially acquired for the production of forest products and for erosion control, water management, and other conservation values, recent changes in policy by the Department recognize the growing importance of recreation and future developments I am sure will see these lands managed to provide limited recreation opportunities.

The Authority has adopted a new multiple-use development policy and is acquiring forest and wildlife areas primarily for reforestation purposes but managed to provide low-intensity outdoor recreation.

The private sector of our community and the part they play in the outdoor recreation picture must not be overlooked. Individuals have acquired substantial acreages of lands for permanent residences and week-end retreats; churches, scouts, guides, fishing and hunting clubs, and many other quasipublic groups have acquired lands for a variety of outdoor recreational purposes. All of these people are assisted by the Authority in establishing forest cover on their properties. We must agree, I believe, that these people are not planting these trees for their potential harvest, and they are not primarily concerned with their conservation value. These trees are planted to provide the attractive setting so important to the development of the outdoor recreation environment.

In the lower reaches of our main valley systems, the Authority is acquiring extensive areas of valley lands to prevent their development for urban purposes and to preserve their primary function of carrying out excessive flood flows. These lands are leased to the Metropolitan Toronto Parks Department for development for recreational purposes. These lands, in many instances, have been badly damaged by urbanization. Here again, the Authority in co-operation with the Parks Department, is pursuing a programme to rehabilitate these lands through extensive tree planting programmes.

\section{OUTDOOR RECREATION AND EDUCATION}

One problem that cannot be overlooked in the fantastic growth of leisuretime activities is the ability of people to make productive use of this newfound time. Outdoor recreational activities can be better enjoyed by a fuller knowledge and understanding of the outdoors.

Claude Robillard, in his background paper for the "Resources For Tomorrow Conference", put the problem in its proper perspective - "Half of the people believe that spare time gives an opportunity to do nothing at all. I am more interested in the other half - in those who believe that spare time is a gift that enables us to do something different, rather than nothing at all!" The forest environment plays a dominant role in most outdoor educational endeavours.

Again, let us explore the activities of the Metropolitan Toronto and Region Conservation Authority to illustrate the need and the demand for a greater knowledge and understanding of the outdoor environment.

Nature Trails, with small trailside displays, are extensively used by the general public, and these are supplemented by regularly conducted Nature Hikes by qualified guides. Special programmes are offered throughout 
the Summer to provide the public with an opportunity to explore to greater depths the natural phenomena with experts in their particular fields.

The Authority has programmed special hikes to provide interested people with an opportunity to learn more about our outdoor environment. Geology tours, wildlife tours, and forestry tours are examples of this type of activity. Professor Armson, your Annual Meeting Chairman, and other Professional Foresters have co-operated in conducting these hikes.

Organized youth groups provide another splendid opportunity for conservation education. The majority of such groups are dependent upon a forest environment for their purpose. 4-H Forestry Clubs, Resource Rangers, Scouts, and Guides, have all used the facilities provided by the Authority for outdoor education purposes.

The educational systems are becoming increasingly more interested in outdoor education, and in the study of the natural sciences in the out-of-doors. While many of us are only a generation, or less, "off the land", the trend to urban living and the concentration of a large segment of our population in metropolitan regions will result in the majority of the people having little or no knowledge of our natural resources and the part that they play in the web of life. Education people are increasingly recognizing this problem and are providing opportunities for school children to observe some of the principles taught in the classroom in an outdoor setting. Woodlands and a forest environment play a most important part in this aspect of education. Examples of this type of activity are 1-day tours of woodland nature trails, visits to County Forests, and Provincial Forest Nurseries.

One important development in this field is the provision of opportunities for extended study in the outdoor environment. Germany, England, and Scotland have a long history in this type of education and there are many regions in the United States where similar opportunities have been available for some time. In the Metropolitan Toronto area there are two outdoor education centres - one of which is the Metropolitan Toronto Island Natural Science School, operated by the Toronto Board of Education; and secondly, the Albion Hills Conservation School, operated by the Metropolitan Toronto and Region Conservation Authority.

The forest plays an important role in the Albion Mills Conservation School since one-half of the 1-week study period is spent in a woodland environment. The students are provided with an opportunity to study some simple forest management principles. They are taught tree identification, plant identification; and are introduced to ecology; cruise a quarter-acre woodlot using calipers, diameter tapes, biltmore sticks, and abney levels. They observe woodlot operations, tap and make maple syrup and plant trees in the appropriate seasons.

The Ontario Forestry Association has sponsored similar schools in the Northern parts of Ontario. Although the children live in close proximity to extensive forest areas, they live in urban centres and have little opportunity to gain a first-hand experience and knowledge of resource management.

I believe that you will see considerable growth throughout Canada in this type of education and, unquestionably, a forest environment will be one of the prime requisites. 


\section{CONCLUSIONS}

The concentration of a large proportion of our population in urban areas, and more particularly in large metropolitan areas, together with increased leisure time, income, and greater mobility, will create unprecedented demands for open space for outdoor recreation. A very substantial part of the demand will be for areas within seventy-five miles of urban centres.

Extensive areas which will provide a wide range of outdoor recreational opportunities to meet the needs of a variety of social and cultural groups will be required.

Water is a basic ingredient for outdoor recreational activities. Nevertheless, the forest environment is necessary for a wide range of outdoor activities. It is essential that proper planning take place to ensure that a substantial proportion of the woodland areas adjacent to metropolitan centres are acquired and preserved for recreation purposes. Management of existing woodlots and planting to provide additional areas will be required to provide the areas necessary for future generations.

One of the problems of increased leisure time is the productive use of this time. An opportunity is presented to use facilities, and more particularly forest areas, to study natural resources and their management.

The concentration of population in urban centres will mean that a substantial proportion of our people will have little or no contact with natural resource management. Education has a responsibility to provide students with opportunities to study resources management in the outdoor setting. This can be accomplished through field trips and conservation schools. There will be a substantial increase in outdoor education in the future and the forest will play an important part in this programme.

In conclusion, I should say something about the role of the Forester in outdoor recreation and education.

A Professional Forester, by his nature and by his training, is well equipped to understand and sympathize with the growing demands for outdoor recreation. He has a broad general knowledge of a wide range of resource management problems and is ideally equipped to administer programmes to meet the needs of increased outdoor recreational activities, including outdoor education.

I foresee a considerable future for Professional Foresters in this field.

\section{REFERENCES}

"Outdoor Recreation For America" - A report to the President \& to the Congress by the Outdoor Recreation Resources Review Commission, Jan./62, Washington, D.C.

"Proceedings of the Resources For Tomorrow Conference", Volume III, October 1961, Queen's Printer.

"Background Papers of the Resources For Tomorrow Conference", Volume 2, July 1961. 